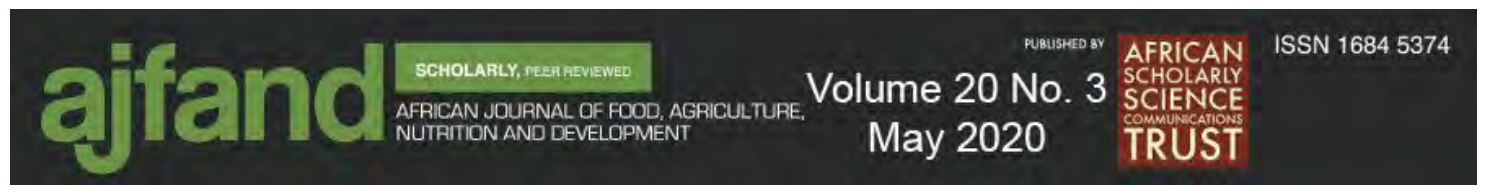

Afr. J. Food Agric. Nutr. Dev. 2020; 20(3): 15779-15799

DOI: 10.18697/ajfand.91.18530

\title{
REVIEW ON INCREASING IRON AVAILABILITY IN SOIL AND ITS CONTENT IN COWPEA (VIGNA UNGUICULATA) BY PLANT GROWTH PROMOTING RHIZOBACTERIA
}

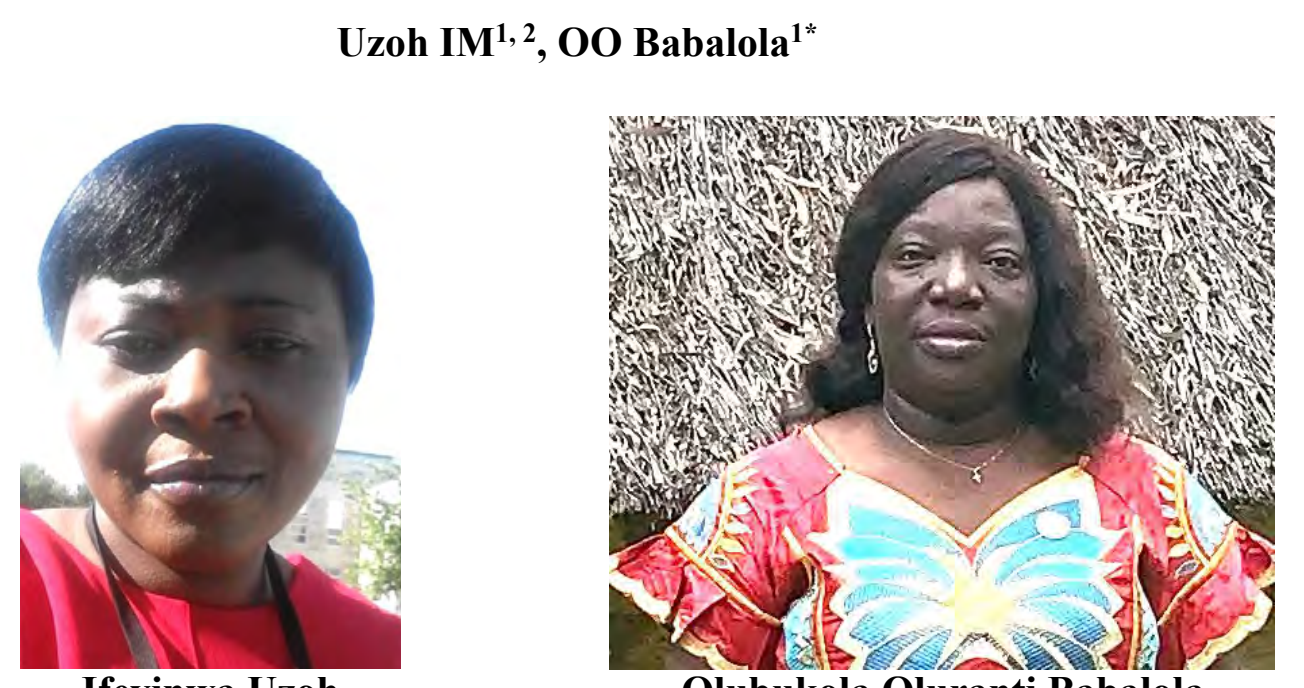

Ifeyinwa Uzoh

Olubukola Oluranti Babalola

*Corresponding author email: Olubukola.Babalola@,nwu.ac.za

${ }^{1}$ Food Security and Safety Niche Area, Faculty of Natural and Agricultural Sciences, North-West University, Private Bag X2046, Mmabatho 2735, South Africa

${ }^{2}$ Department of Soil Science, University of Nigeria, Nsukka 


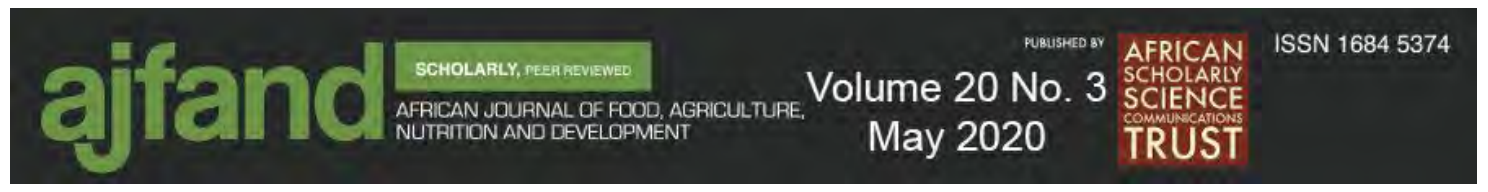

\section{ABSTRACT}

Iron $(\mathrm{Fe})$ deficiency constitutes a serious health challenge in humans especially in children and pregnant women, causing anemia and lower cognitive ability. In subSaharan Africa, consumption of cowpea (Vigna unguiculata) is suggested as a means to tackle Fe deficiency in humans better than other plants including vegetables. This is because cowpeas are the staple food, they contain other nutrients including protein, carbohydrate and vitamins and their cultivation sustains the environment through nitrogen fixation. Iron though rich in soils exhibit low solubility thereby limiting phytoaccumulation in cowpea, leading to the production of poor Fe cowpea. Plants that are Fe efficient developed two strategies to increase Fe availability and absorption. As a strategy 1 crop, cowpea acquires iron significantly through rhizosphere acidification; which reduces $\mathrm{Fe}^{+3}$ to $\mathrm{Fe}^{+2}$. Such mechanisms do not deliver enough $\mathrm{Fe}$ to the crop to meet their demands. Application of inorganic Fe fertilizer to soil though not sustainable also results in fixation and unavailability of Fe to plants. This review surveys available literature on the use of plant growth-promoting rhizobacteria (PGPR), which are costeffective, eco-friendly and sustainable for enhancing $\mathrm{Fe}$ mobility for increased absorption by the plant. Recent biotechnological advancements in rhizosphere organisms have revealed various techniques involved in growth enhancement by PGPR. Such growth enhancement involves mobilization of Fe in soils for ease of absorption by plants. Iron solubilization by PGPR as a direct mechanism is facilitated by several microbes including Fluorescent pseudomonad, Bacillus, Agrobacterium, Sinorhizobium and Bradyrhizobium japonica. They do this through different mechanisms, which include bioleaching, chelation, biomethylation and siderophores mediated iron uptake. The functional groups responsible for the binding of iron to siderophores are mostly the hydroxymates and catechols. Siderophores are iron binding compounds which are released by both plants and microbes. Cowpea like other non-gramminacae crops, interact with microorganisms to acidify the rhizosphere. Thus, chelates of ferric reductase and iron (II) transporters are activated in the roots. Microorganisms especially bacteria and fungi now chelate insoluble $\mathrm{Fe}^{+3}$ and make them available for plant uptake. Plants are capable of utilizing siderophores produced by microorganisms for Fe uptake. Therefore, these bacteria should be inculcated into the cultivation of cowpea so that its Fe content will be enriched. With the consumption of iron-rich cowpea, Fe deficiency will be minimized if not completely eradicated.

Key words: Biofortification, microbes, iron-deficiency, siderophore, bioleaching, biomethylation, bioavailability, catechol 


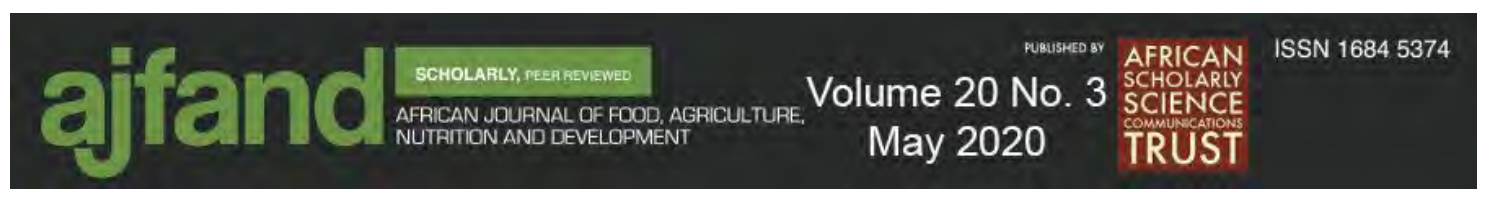

\section{INTRODUCTION}

Iron deficiency constitutes a global public health concern and combating it is regarded as one of the ten major threats facing the human race. Consumption of high calorific food poor in vitamins and minerals predisposes an individual to micronutrient deficiencies. In sub-Saharan Africa and most rural communities, diversification of food is limited due to low income and poor livelihood. As a result, animal sources with high heme iron or iron food supplement is not consumed sufficiently, with resultant Fe deficiency in many individuals. Micronutrient deficiency hampers the mental and physical development of young people. Bhullar and Gruissem [1] traced micronutrient deficiency to insufficient $\mathrm{Fe}$, zinc $(\mathrm{Zn})$ and vitamin $\mathrm{A}$ in foods consumed by individuals. In addition to the consumption of poor micronutrient food, Fe deficiency anemia according to AlChoubassi et al. [2] results from its low bioavailability and high levels of inhibitors to human $\mathrm{Fe}$ absorption in stable food crops.

Iron plays diverse roles in the body such as the formation of haemoglobin; an oxygencarrying blood component, synthesis of deoxyribonucleic acid (DNA), production of connective tissues, the neurotransmitters in the brain and enhancement of immune system [3]. Very importantly, all living things including microorganisms require $\mathrm{Fe}$ as essential nutrient. Iron is usually abundant in the soil, but highly insoluble, thus marginally available for plant uptake. In high $\mathrm{pH}$ and well-aerated conditions, like the cultivated land, Fe availability is very low [4] that is, 100 times less than the needed quantity for the best plant growth. As a result, low availability of Fe occurs regularly during crop production often in non-acidic soils. This is regarded as important environmental stress in agriculture since $30 \%$ of cultivable land has high $\mathrm{pH}$ unsuitable for iron uptake $[5,6]$

Proper understanding of mechanisms of iron uptake from soil and its storage in edible parts motivates the study of increasing plants' iron content. These storage organs like the seed are staples (such as cowpea) for human consumption. Vegetables and legumes are key plant sources of iron. Cowpea with its multifaceted benefits are chosen in this review as a means to handle iron deficiency. Cowpea is an important leguminous crop and grows in warmer regions all over the world particularly in swaths of sub-Sahara Africa and north-eastern Brazil. It supplies high protein seed and fodder hence it constitutes an important part of cropping systems. It is also a regular meal in most families and it is now used as a constituent of baby food. Therefore, biofortification of cowpea with Fe can be a veritable tool in addressing Fe deficiency in humans especially the poor.

Biofortification is the course of cultivating crops with high micronutrient content through several strategies including modern biotechnology. Crops with acceptable agronomic and consumption records are targeted for enrichment with micronutrients. Plant breeding, nutritional genetic modification, fertilization and recently the use of plant growthpromoting rhizobacteria (PGPR) are such biofortification strategies. Importantly, the application of PGPR as beneficial soil microorganism in agriculture has been of great benefits. Owing to the high cost of inorganic fertilizers, their negative effects on human and environmental impact hence PGPR as a group of beneficial bacteria that enhances plant growth has been a point of focus [6]. Moreover, inorganic Fe fertilizers are easily transformed into unavailable forms when applied to the soil. Organic sources such as 


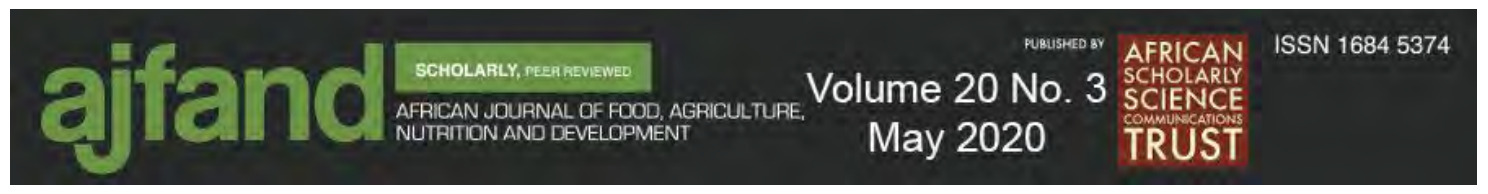

composts, farmyard manures, plant residues, organic chelates and organo-iron complexes are also useful organic fertilizers for ameliorating Fe deficiency. According to Shenker \& Chen [7], there has not been any ultimate solution to tackle Fe-deficiency in all the crops. Research has proven that PGPR is more effective as a plant growth improving agent when compared with other agricultural inputs like pesticides, insecticides and synthetic fertilizers [6]. Plant growth-promoting rhizobacteria enhances plant growth maintains a safe environment and increases agricultural productivity. Some examples of soil PGPR are Azospirillum, Erwinia, Burkholderia, Enterobacter, Pseudomonas, and Mesorhizobium. Plant growth-promoting rhizobacteria have the capability of producing plant hormones and siderophores which affect plant growth through metabolism regulation and making nutrients like Zinc, Iron, Copper and Manganese available in the soil for plants absorption. These hormones tend to improving plant growth even under stressful conditions.

This research brings into focus the invaluable role Fe plays in maintaining the wellbeing of an individual and inevitable health challenges posed since its deficiency is a global challenge. Consumption of food rich in Fe helps in combating Fe deficiency; cowpea can, therefore, be enhanced to achieve such a role. This is because of the numerous advantages attached to its cultivation and consumption. The paper also discusses the plants' intrinsic strategies for combating the insolubility of iron in the soil. This has neither sufficiently supplied the plants' iron demand nor enriched cowpea with iron sufficiently required by humans. It further presents discuss of an intervention among all interventions, which is economically and socially sustainable and recompense to the poor. The use of PGPR in increasing solubility and uptake of iron in cowpea is such an intervention. The mechanisms and processes in use for iron mobility and solubilization are enumerated. It is believed that this knowledge would assist in remediating problems of Fe immobility, thus increasing iron content in crops. As a result, human-related iron deficiency health challenges would have been abated.

\section{COWPEA}

\section{Relevance of cowpea production, an African perspective}

Cowpea is a multi-faceted crop because it is used for food and nutrition security and soil production sustainability. In Africa, especially among the rural communities, consumption of animal proteins are either unaffordable or sparsely eaten. Cowpea, a protein-rich food, which is cultivated in these rural communities are a suitable alternative not only as a protein source but also a means to reduce micronutrient deficiency. Cowpea constitutes key important food for millions of people, especially in sub-Saharan Africa because it's the major source of protein for the world population. This crop is special and useful in Africa because most of the global cowpea $(>90)$ is produced in sub-Saharan Africa, mostly from West Africa and particularly in Nigeria and Burkina Faso [8]. Cowpea in addition to its high nutrient content is also rich in nutraceuticals such as dietary fiber, antioxidants, polyunsaturated fatty acids (PUFA) and polyphenols [9]. Table 1 shows the nutritional content of cowpea flour. As shown there, its Fe content is comparable to findings of [10], but there were varietal differences in cowpea iron content ranging from $15.61-40.08 \mathrm{mg} 100 \mathrm{~g}^{-1}$ dry weight. So could be used to reduce micronutrient deficiency in urban and rural dwellers. 
In addition, cowpea fixes nitrogen when cultivated. As a result, its cultivation supplies nitrogen to the following crop or that intercropped with it. This reduces nitrogen $(\mathrm{N})$ fertilizer requirement of cropping systems thereby increasing soil sustainability. In most African countries, fertilizer availability and distribution has been a serious problem, either they are not provided on time or distributed inadequately. Besides, fertilizer production especially fertilizer $\mathrm{N}$ is a high energy-requiring process and unsustainable. It has also detrimental impact on the environment especially when applied in excess. Therefore, cowpea cultivation plays a major role in reducing fertilizer $\mathrm{N}$ requirement in sub-Saharan Africa.

\section{Importance of cowpea in human nutrition}

According to Babalola et al. [11], the most consumed legume in West Africa is cowpea (Vigna unguiculata) especially in Nigeria, Niger, and Burkina Faso. Figures 1 and 2 show the picture of a black-eyed cowpea and its vegetative part. It is cultivated in the semiarid zones of Africa, America, Asia, and Europe. Cowpea in Africa and other tropical zones is an important leguminous crop with its seed rich in nutrients. According to ZiaUl-Haq et al. [12], cowpea has been consumed from ancient times and it is rich in soluble and insoluble dietary fibers. In sub-Saharan Africa, every part of cowpea is used as food for instance, during fruiting stages, the green pods are eaten as a vegetable while its dried seed can be cooked or grounded into slurry to make cowpea cakes.

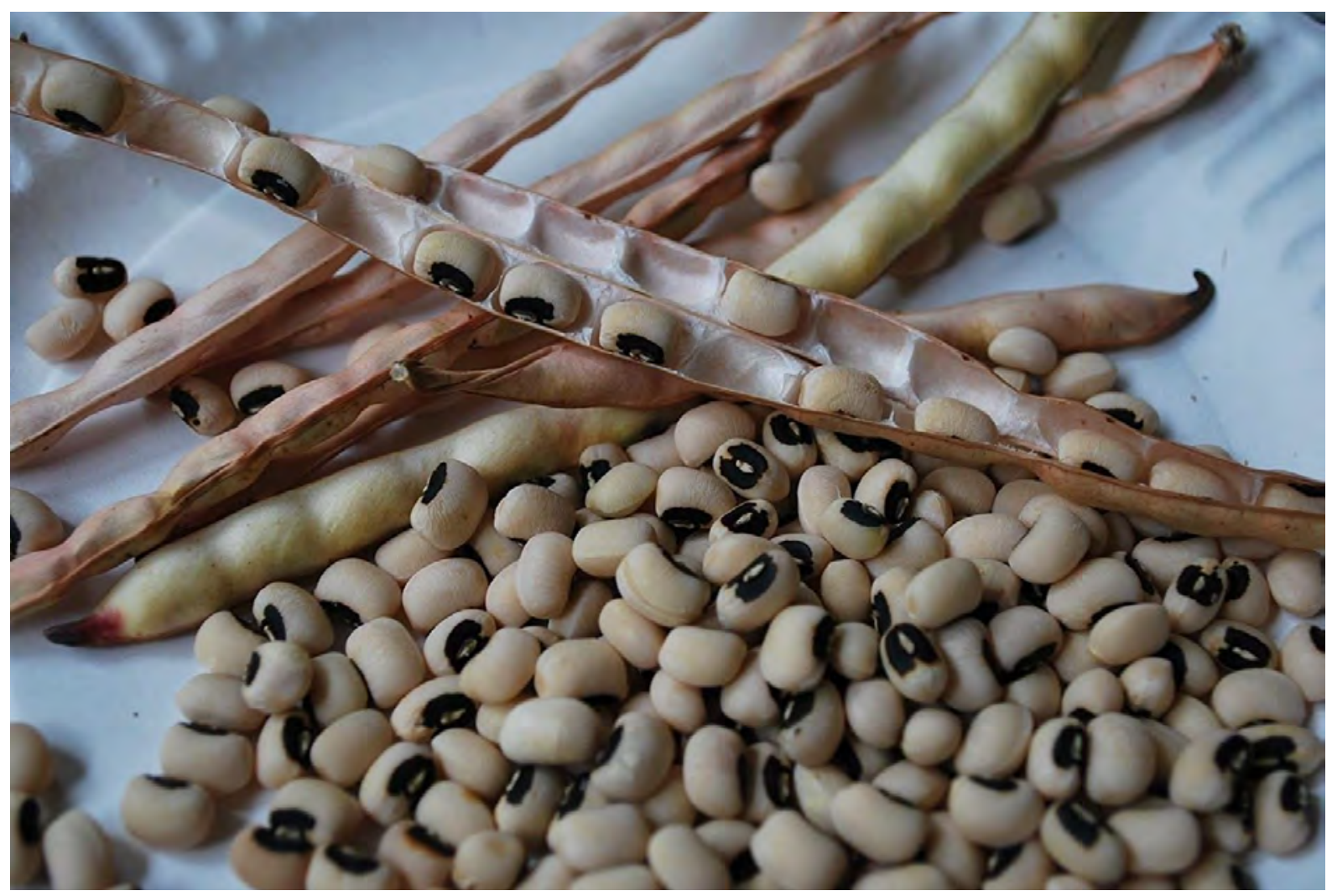

Figure 1: Black-eyed cowpea seed and pod 

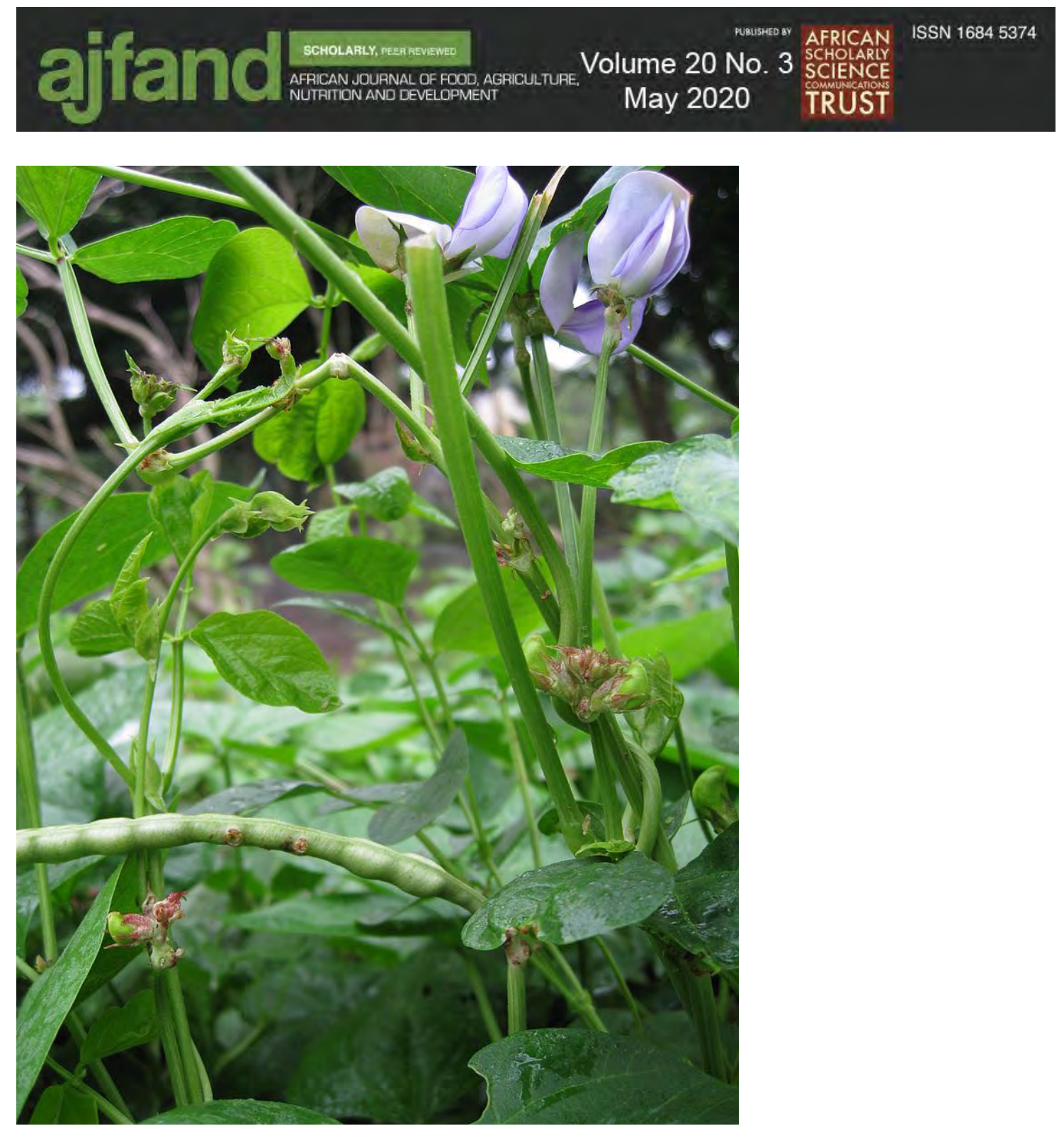

Figure 2: Cowpea vegetative part

Furthermore, the leaves are fodders fed to animals, which makes no part of cowpea a waste. Liquor can also be produced from cowpea seeds with spices considered medicinal in curing common cold and also considered diuretic and has the potential of destroying stomach worms. For further preservation, cowpea leaves can be processed and then stored for future use. People in Sudan and Ethiopia eat cowpea roots [12]. Additionally, cowpea contains amino acid profile which complements cereal grains; it also contains an average $23-25 \%$ protein and $50-67 \%$ carbohydrate thus adding to its importance to human.

Mani and Vibha [13] prescribed that cowpea is rich in iron, fiber and folic acid. Apart from being a multipurpose crop, research has proven that the consumption of cowpea tends to prevent cardiovascular and metabolic diseases. Owing to its advantages, global production has increased from 1.3 to 7.0 million tons between 1981 and 2013. Figure 3 shows the production areas in Africa. With this increased production, cowpea most likely contributes significantly to the human protein demand. Adding to the rich nutritional 


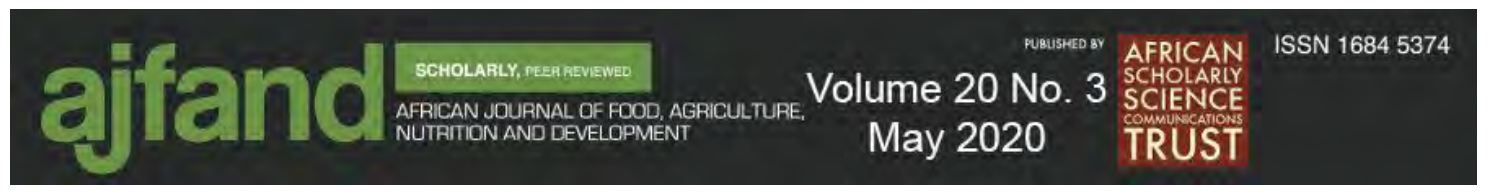

content of cowpeas, generally, they contain bioactive compounds that are of great importance as nutraceuticals for human health.

Based on the aforementioned, cowpea can be used to tackle iron deficiency in humans. This is supported by the work of dos Reis Moreira-Araújo and Brandão [14] that cowpea flour can be used to prepare products for controlling iron deficiency anemia in children. According to da Silva and Santos [15], biofortification of cowpea (Vigna unguiculata (L.) Walp.) will have a great impact in semi-arid regions because it is a rich source of food, especially of iron and zinc.

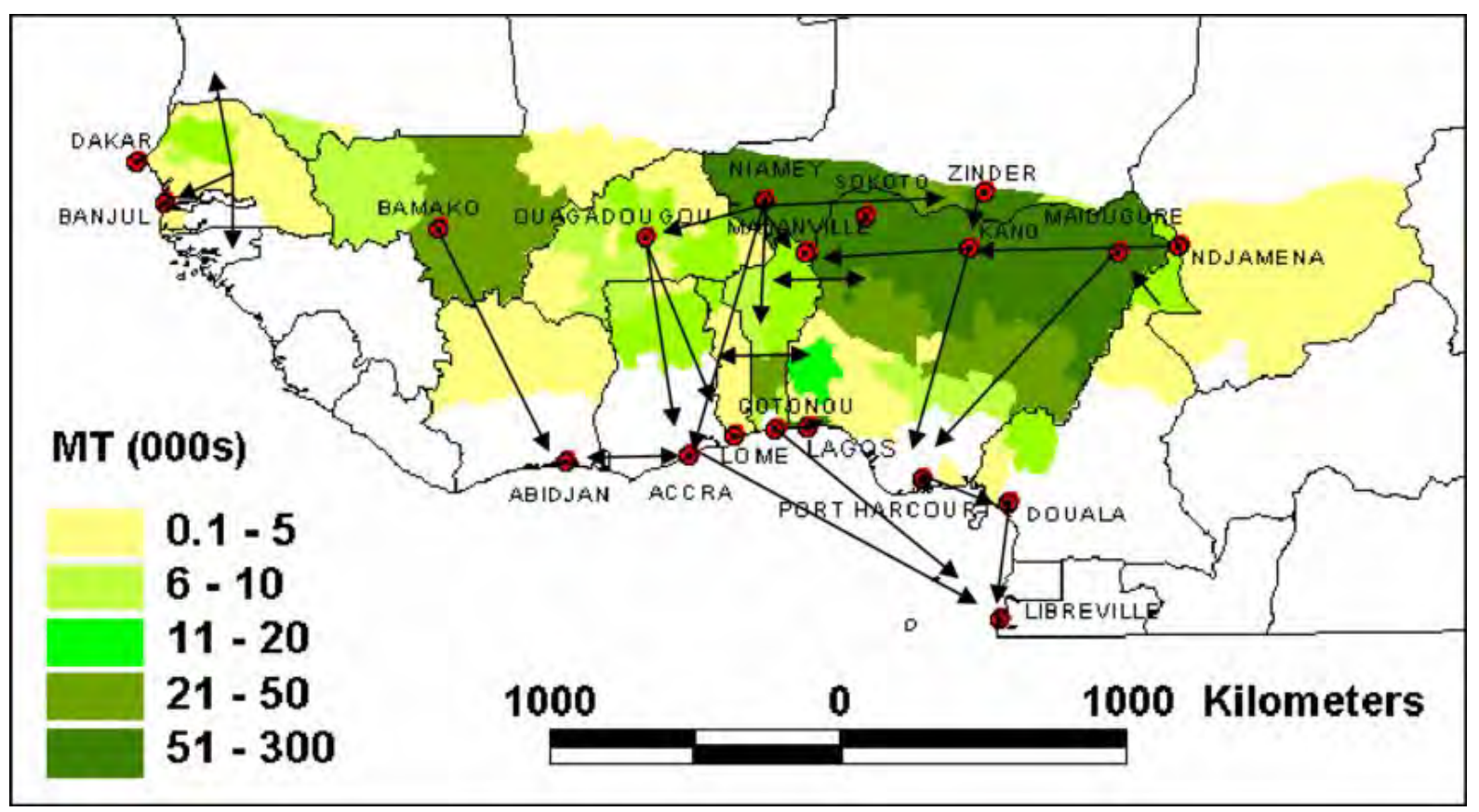

Figure 3: Distribution of cowpea production and movement in West and Central Africa. Arrows indicate the major movement of cowpea grain trade Adapted from Langyintuo et al. [41]

\section{IRON}

\section{Deficiency and its nutritional role in humans}

Iron is a requisite constituent of every living thing. Its earliest recognized role is in hemoglobin synthesis and oxygen transport. Consequently, $\mathrm{Fe}$ is a major constituent of iron-containing proteins [16]. Table 2 shows the iron requirement of individuals according to age. This ranges from 0.61 to $2.38 \mathrm{mg} \mathrm{day}^{-1}$ whereas the iron content of the grains ranges from 15 to $115 \mathrm{ug} \mathrm{g}^{-1}$. These concentrations are low, so there is an urgent need to increase the staple Fe content for Fe deficiency to be eradicated in humans.

Iron deficiency is regarded as the most widespread health challenge globally. It is a major cause of anemia. Over 1.7 billion people suffer from iron deficiency. As a result, over 60,000 women die annually during pregnancy or at childbirth [17]. According to Osendarp and Eilander [18], the most ubiquitous sole deficient nutrient in both developing and developed countries is iron. Iron deficiency anemia is strongly associated 


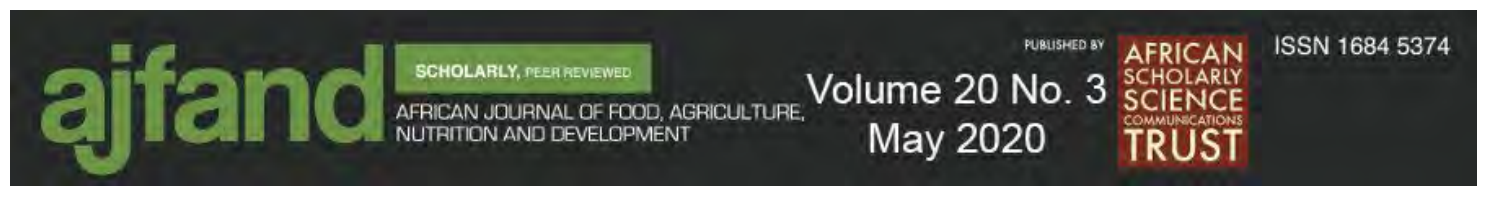

with lower developmental ratings in infants and cognitive ability in children. They also confirmed that the major deficits in early iron deficiency symptoms are a poor response to innovation and orientation among growing children [18]. In addition to the effect of Fe deficiency on the fetal brain development, it could also affect kidney, liver, and placenta development. Insufficient Fe can lead to complications as one grows up. The commonest symptoms include anemia, fatigue and reduced capacity for exercise tolerance. Therefore, Fe plays a principal role in maintaining wellbeing across the lifetime.

To forestall this challenge in humans, different strategies have been devised to fortify humans with iron either through drugs, food diversification, food fortification or biofortification (Table 3). The content, merits, and demerits of each intervention are depicted in table 3. Sharma et al. [19] noted that interventions including drugs, food diversification, and fortification have not been fully successful. As a sequel to the shortcomings of others and unaffordability by the poor, this discourse targets a type of biofortification using PGPR, which is an enrichment of staples with Fe during cultivation by these groups of bacteria.

\section{Methods of Iron acquisition in plants}

Naturally, crop plants device means of overcoming iron deficiency. Iron efficient plants evolved two major strategies to acquire poorly bioavailable Fe in the soil [20]. Usually, microorganisms always struggle with plant roots for the available iron. Strategy 1 plants known as dicotyledonous and non-gramminaceous monocots reduce $\mathrm{Fe}^{+3}$ to $\mathrm{Fe}^{+2}$, which is the most important mechanism for iron acquisition for these plants and is catalyzed by ferrous reductase oxidase. They do this through the rhizosphere acidification process. The roots excrete positively charged ions into the rhizosphere, thus reduce ferric ion to the more soluble ferrous $\mathrm{Fe}$ and the absorption of the ferrous ion into the root by the Iron Regulated Transporter 1 (IRT 1). Secondly, these strategy 1 plants also release organic compounds that reduce $\mathrm{Fe}^{+3}$ to $\mathrm{Fe}^{+2}$ and chelators (such as phenolic compounds, flavins and organic acids) that bind $\mathrm{Fe}^{+3}$ thus enhancing iron availability. According to Schmid et al. [21], the second mechanisms offer a minor contribution to iron availability. In addition to proton release, strategy 1 plants release carbohydrates, amino acid, siderophores, phenols, enzymes and acids that make iron available for absorption. Furthermore, strategy 1 plants are noted for developing morphological changes in tackling iron deficiency such as proliferation of lateral roots. They change their morphology and physiology which assist in transforming the limited soluble iron for their use. The factors enhancing this proliferation are yet unknown. It could be as a result of interaction with mycorrhizae and other beneficial organisms. More so, genes regulate iron availability in response to the iron levels in the soil. These genes associated with iron absorption are expressed during iron deficiency. Iron response transporter 1 takes up iron from the soil to the plants despite the limited available quantity as attested from model plant Arabidopsis thaliana. Iron response transporter 1 plays the major function regulation of iron. These activities boost plant functioning under conditions where soil iron is minimal.

The second group of iron efficient plants known as strategy II are the gramminaceous plants. They acquire iron from $\mathrm{Fe}^{+3}$ bound to organic compounds (phytosiderophores) 


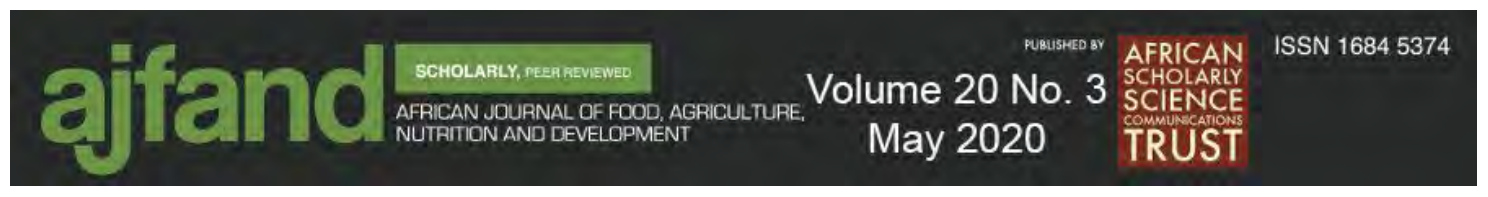

[22]. Plants release the phytosiderophores into the rhizosphere, which then binds $\mathrm{Fe}^{+3}$ to form complex compounds. Despite all the strategies employed by both strategy I or II plants, recently, it has been found these mechanisms are neither sufficient to prevent the plants from Fe deficiency in limited soils nor meet up with human iron requirement [23]. To increase the intake of Fe through food consumption, plants must absorb a sufficient quantity of iron from the soil and make them bioavailable when consumed. The use of genetically modified foods is a viable option but has problems of ethical approval by many communities. One of the most recent research in plants' $\mathrm{Fe}$ and micronutrient acquisition stems from associated rhizobacteria, with PGPR being notable for nutrient mobilization in plants [24]. Microorganisms form siderophores that bind ferric $\mathrm{Fe}$ because they are more efficient than plants in the acquisition of iron. As a result, plants benefit from the iron since they can utilize siderophores formed by microorganisms.

\section{Biofortification using plant growth promoting rhizobacteria}

Biofortification targets sustainable and cost-efficient production of staple crops with the intent to increase nutritional value, and thus reduce micronutrient deficiencies. Staples are foods consumed constantly in high quantity, which dominates the standard diet in a community. As a result, there is a significant relationship between staple food consumption and nutrition of such poor rural communities with rarely other means of nutrient supplementation. In comparison to other nutrient fortification, biofortified foods contain a lower amount of essential nutrients and vitamins but they do satisfy the micronutrient requirement of an individual. Its advantage is that it offers the rural dwellers the opportunity to satisfy their nutrient demands from staples within their community. Such biofortification techniques include agronomic biofortification, conventional breeding, and nutritional genetic modification [25]. The use of PGPR is an aspect of agronomic biofortification. These sets of bacteria are posited as enhancers of iron accumulation in staples in addition to increasing crop yield and fertility of soils.

Plant growth-promoting rhizobacteria are microbes with special abilities in promoting the productivity of plants. These microbes undertake different biotic functions in the soil ecosystem to maintain agricultural productivity. They modulate plant hormone levels, sequester soil toxic heavy metal or directly facilitate plant growth through the uptake of phosphorus, micronutrients or indirectly by suppressing the activities of pathogens that hinder growth and development of plants.

Plant growth-promoting rhizobacteria inhabit plant roots or the rhizosphere, from there promote plant growth by producing and secreting different substances that help in the regulation of nutrients in the vicinity of the rhizosphere. According to Alori et al. [26], inoculation with PGPR enhances nutrient solubility and uptake. The direct effect of PGPR on plant growth occurs when they aid the acquiring of nutrients from its surroundings.

\section{PGPR in nutrient mobilization for plant uptake}

Plant growth-promoting rhizobacteria maintains the availability of soil nutrients through some interesting mechanisms. These are solubilization of mineral nutrients, degrading organic pollutants, biocontrol of soil pathogenic organisms, decomposition of organic matter, promoting changes in vegetation, recycling of essential elements and producing 


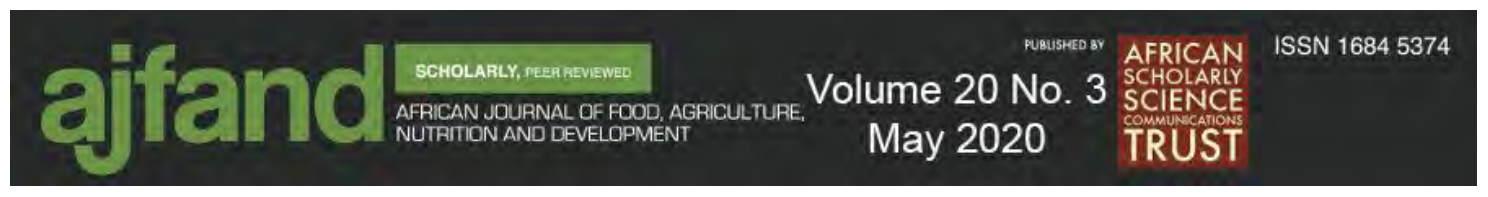

multiple growth regulation in plants. Plant growth-promoting rhizobacteria enhance bioavailability of soil nutrients thereby increasing productivity. According to them, PGPR colonizes soil rhizosphere, therein acts as a biological control against soil-borne pathogens, decompose organic matter, and promote root growth and biologically fix nitrogen. Through these mechanisms, it brings closer to plant roots both macro and micronutrients such as the ones produced by siderophores for Fe chelation. Several studies have shown that PGPR increases the iron availability of plants in soils $[27,28]$. Inoculating plants with PGPR are effective both at the molecular and physiological level. They do that through both direct and indirect mechanisms; most times they modify and improve plant root functioning and influence their general physiological balance. Meanwhile, these PGPR has the potential of triggering a systemic response to make nutrient available through some unknown signalling mechanisms. Scientists have used plant transcriptomic and metabolic responses to prove the significant role PGPR plays in the functioning and physiology of plants [29]. Plant growth-promoting rhizobacteria are more effective in the soil due to their capability in synthesizing different substances which enables them to turn around all the microbial community in the soil rhizosphere niche.

\section{PGPR and iron mobility in cowpea}

The function of microorganisms in reducing metal and increasing their mobility is an essential aspect of geochemical cycles [30], thus enhancing the productivity of plants and wellbeing of the people. By mediating effects on release or fixation processes, they determine the quantity of metal available in soil solution. Mobilization of metals can be facilitated through the release of positively charged ions, secretion of binding agents, and other chemical changes. Plant growth-promoting organisms offer a solution to iron mobilization during plant growth. Table 2 shows the effect of Bradyrhizobium japonicum (a PGPR) on the iron content of different parts of cowpea, which shows an improvement of iron content in cowpea as a result of inoculation of cowpea seeds with the rhizobium [31].

Microorganisms appear to have higher Fe competitive ability than plants. Their close involvement in metal biodegradation of earth materials determines mobility and availability of nutrients. The organism and its environment determine the equilibrium between mobilization and immobilization processes. Mobilization of iron occurs through bioleaching, binding of metabolites and siderophores, and methylation. Soil Fe exhibits poor solubility; but plants and microorganisms interact with each other and with organic substances to enhance its solubility and thus available for plant growth. A major way microbes affect iron solubility in the plant environment is by synthesis of siderophores.

\section{The use of siderophores in iron mobility in cowpea by PGPR}

Sessitsch et al. [32] defined siderophore as iron-binding compounds, released by organisms during iron-restrictive situations. They are also specific low weight iron constituents which aid plants in iron absorption, produced primarily for obtaining iron, but they do bind other minerals [33]. High-affinity ligands transport and store iron in plants and animals. In iron limiting soils, bacteria and other microbes especially fungi produce siderophores. Five hundred compounds have been identified as siderophores. These compounds scavenge for iron from the environment and make them accessible for 


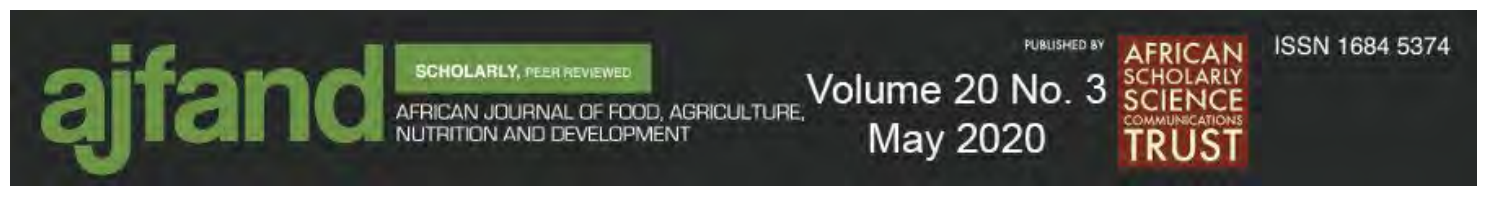

the microbes. Soil is Fe limiting habitats for bacteria though abundant but bioavailability is low, because iron exists as insoluble $\mathrm{Fe}^{+3}$ hydroxides. Siderophores solubilize these Fe hydroxides and in plants is suggested a major microbial activity facilitating Fe nutrition [23]. Siderophore production is widespread in bacteria and is seen as its commonest secondary metabolites.

Siderophores can be derived from several biosynthetic pathway types. Research has shown that most microbes including aerobes and facultative anaerobes produce not less than one siderophore. Microbes that increase iron nutrition in plants do produce siderophores because they have a high attraction for iron and reversibly chelate them [34]. Iron-bound by siderophore is directly absorbed by plants with no further reduction. Some negatively charged oxygen-containing functional groups are responsible for the production of siderophores with high Fe affinity complexes. Such functional groups are alpha-hydroxycarboxylate, catecholate and hydroxamate. Siderophores usually attract $\mathrm{Fe}^{+3}$ instead of $\mathrm{Fe}^{+2}$ or any other micronutrient ion, though complexes with less stability also exist with other micronutrient elements.

According to Rajkumar, Ae, Prasad and Freitas [33], hydroxymates and catechols are mostly the functional groups responsible for the binding of iron to siderophores. In cowpea, rhizobium is notable for the production of siderophores. Rhizobium meliloti produces rhizobactin, a unique structural siderophores. Some others report production of catecholate and hydroxamate type of siderophore. Several root nodule bacteria upon investigation with chrome azurol-S assay, reacted positively, thus signifying the ability to produce siderophores [35]. Also, citrates act as siderophores in Bradyrhizobium japonicum. Thus, rhizobia produce strain-specific types of iron chelators that are structurally different.

Bacillus subtilis and B. pumilus are commercially available biofertilizers that are used either in seed coating or directly applied to the soil during crop cultivation for their growth enhancement. According to Sonbarse, Sharma and Parvatam [27] B. subtilis ability to accumulate iron in several plants has been widely studied. Some of the mechanisms include secretion of volatiles, flavonoids and organic acids that enhance plants own iron acquisition machinery and solubilization. Microorganisms producing siderophore enhances $\mathrm{Fe}$ uptake of cowpea. In strategy 1, crops like cowpea, $\mathrm{Fe}^{+3}$ siderophore chelates are likely formed through a pathway other than reduction pathway.

\section{Autotrophic bioleaching and iron mobility in cowpea by PGPR}

Schippers [36] defined bioleaching as the dissolution of insoluble metal substance into a water-soluble state. The change of $\mathrm{Fe}^{+3}$ ions to $\mathrm{Fe}^{+2}$ ions is a chemical process involving metal sulphide oxidation. In bioleaching, microorganisms oxidize $\mathrm{Fe}^{+2}$ and sulphur substances to produce $\mathrm{Fe}^{+3}$ and protons. These protons attack metal sulphide, lowers $\mathrm{pH}$ and keeps $\mathrm{Fe}$ in solution. Chemolithotrophic and acidophilic bacteria carry out most autotrophic bioleaching because they utilize the oxidized ferrous iron or reduction of sulphur compounds for energy. This process leads to the dissolution of metals since $\mathrm{Fe}^{3+}$ and $\mathrm{H}_{2} \mathrm{SO}_{4}$ are produced $[36,37]$. Thiobacillus thiooxidans, Thiobacillus ferrooxidans and Leptospirillum ferrooxidans are oxidizing bacteria for sulphur, iron and sulfur, and iron, respectively. They are examples of organisms involved in bioleaching. In these oxidation processes, sulfides of these metals are dissolved, resulting in the lowering of 


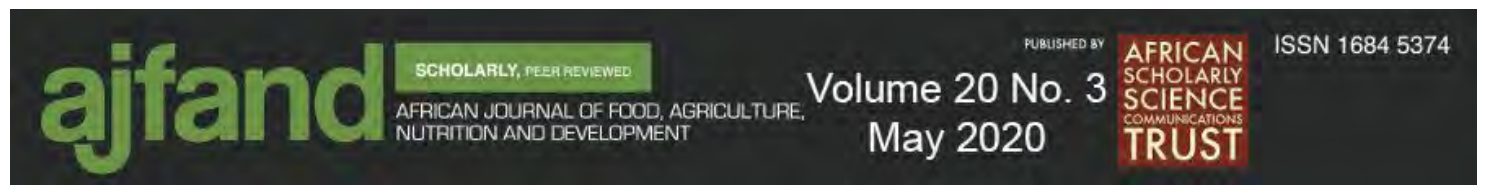

$\mathrm{pH}$ of their close surroundings. As a result, other metal compounds are further solubilized. Industries utilize metal sulfides leaching in biomining of metals.

Heterotrophic (chemoorganotrophic) bioleaching and mobility of iron by PGPR In heterotrophic bioleaching, microorganisms do acidify their surroundings by the production of $\mathrm{H}+$ from membrane ATP, maintaining charge balance or by accumulation of carbon (IV) oxide during respiration. Nitrogen fixation in nodules require proteins made of iron, as a result, legumes have a high demand for iron. Rhizobium thus increases iron uptake in legumes by releasing protons and reducing chemicals, which converts iron $^{+3}$ to iron ${ }^{+2}$. During acidification of metal anionic complex, these metallic elements are released by competition between proton and metal for the anionic complex. Activities of heterotrophic organisms do leach metals because of the abundance of organic acids and chelating agents. Such acids release positive ions and metal-binding anions [38]. Citrate and oxalate anions do bind a large number of metals in a stable form. Oxalic acid also leaches those oxalate complex metals including. Leaching has been utilized in the solubilization of some wastes [38]. According to him, a strain of penicillium leached zinc from zinc oxide gotten from filter dust. It is notable that in both biochemical weathering and soil formation, organic acid production is relevant in the mineral breakdown.

\section{Biomethylation and iron mobility in cowpea by PGPR}

By evaporation of organic compounds that initiate varying expression of transcripts associated with iron homeostasis, iron is made soluble in the soil. In dicotyledonous crops and non gramminaceous monocots, the mechanism for iron acquisition based on reduction strategy is induced [39]. It involves three routes for iron absorption namely proton release to facilitate iron movement, conversion of $\mathrm{Fe}^{+3}$ to $\mathrm{Fe}^{+2}$ and taking in $\mathrm{Fe}^{+2}$. Such Methylation processes are mediated by several aerobic and anaerobic bacteria and fungi. Methyl groups are attached to the metal through an enzyme. Several metals can be transformed by a given species. These methylated metal compounds have varying solubility.

\section{CONCLUSION}

The quality of food consumed by an individual determines the health and wellbeing of such an individual. Quality of food is determined by the quantity and type of nutrients it contains. Iron is a known single most essential micronutrient globally. Its deficiency affects the cognitive and overall wellbeing of an individual. To tackle this problem requires that iron consumption must be increased. Several fortification strategies have met serious limitations, especially as regards affordability by the rural poor. Biofortification, a process of increasing micronutrient content of cultivated crops is aimed at the reduction of malnutrition and its detrimental consequences on humans. Agronomic biofortification utilizes fertilizers including biofertilizers in increasing the nutrient content of crops. Biofertilizers include the plant growth-promoting rhizobacteria (PGPR) which are notable in increasing plant growth. Although inorganic and organic fertilizers have been in use for increasing $\mathrm{Fe}$ in crops, the problem of sustainability, affordability, environmental implication and transportability has limited its use. Moreover, PGPR do also improve their utilization efficiency. Cowpea, a staple crop widely used as a food source and a cheap protein source for the poor, is naturally endowed with rhizobium, a nitrogen fixer and a PGPR. As a PGPR, it is utilizable in 


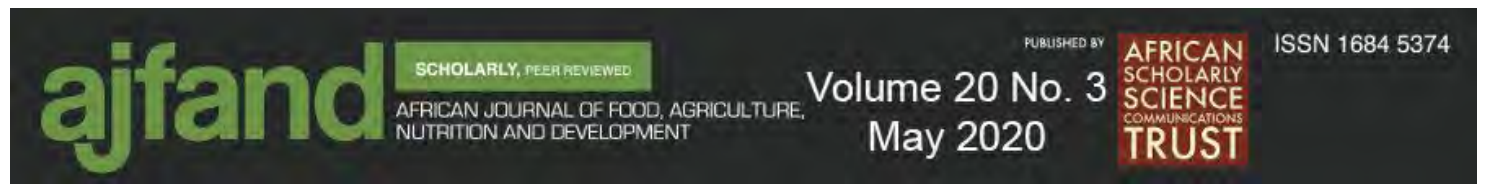

remedying the problem of iron deficiency. Iron, though naturally abundant in nature, is highly insoluble and unavailable for plant uptake. Plant growth-promoting rhizobacteria have been implicated in increasing the solubility of iron. Mechanisms employed by PGPR in increasing solubility of iron in cowpea include siderophores production, autotrophic bioleaching, heterotrophic bioleaching, and biomethylation and redox transformations. The major functional group include hydroxymates and catechols. Evidence abounds in increased iron concentration in cowpea grains inoculated with PGPR. Therefore, the use of these organisms should be expanded and utilized in the cultivation of cowpea so that iron accumulation will be increased and malnutrition if not eradicated will be substantially reduced.

\section{FUTURE PROSPECTS}

More effort and research should be geared towards identifying more bacteria known for iron solubilization and their mode of operation. Few researches on cowpea iron fortification using PGPR exist. Government policies should facilitate production and commercialization of biofertilizers just like the inorganic fertilizer production. More so, farmers should have access to these biofertilizers and they should be encouraged to use them in cowpea and crop cultivation.

\section{ACKNOWLEDGEMENTS}

UIM received a stipend and research support from the North-West University postdoctoral scheme. OOB would like to thank the National Research Foundation, South Africa for grant that supports research in her laboratory (Ref: UID123634).

\section{AUTHOR STATEMENTS}

The authors contributed equally to the development of this article.

\section{CONFLICT OF INTEREST}

The authors declare no conflict of interest

\section{CONTRIBUTION TO THE FIELD STATEMENT}

Nutrient availability is fundamental to crop production and nutrition security of the people consuming the crop. Iron, an essential nutrient, is required for the proper functioning of the human system. Its deficiency is of global concern. It causes lot of dysfunctionality such as anaemia and low cognitive behaviour. Interventions for enhancing iron to humans have not been fully successful especially concerning the rural people and low-income earners. Biofortification has been suggested as a sustainable means of solving this problem, which is the enrichment of crops with iron during cultivation. Iron is highly immobile in the soil so availability and absorption by plants are usually poor. Plants' intrinsic ability for solubilizing soil iron is deficient soils is still insufficient to meet their requirement for iron. Soil Microbes especially the plant growthpromoting rhizobacteria have implicit mechanisms for increasing iron mobility and availability to the associating plants. Inoculation of plants with these microbes or enhancement of the natural occurring ones would lead to increased iron mobility and enriched iron produce. 


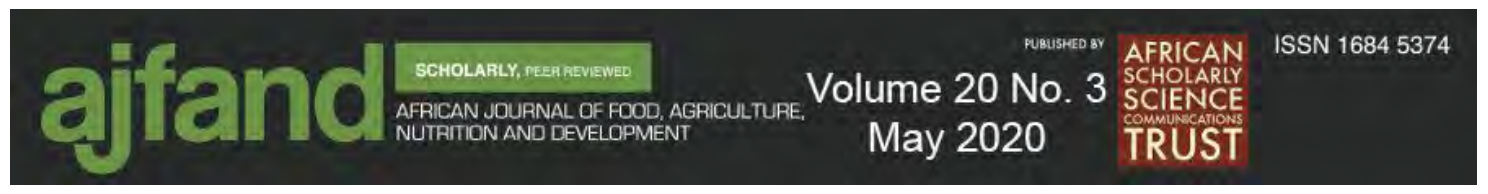

Table 1: Nutritional content of cowpea flour

\begin{tabular}{ll}
\hline Nutritional factor $\left(\mathrm{g} 100 \mathrm{~g}^{-1}\right)$ & Quantity contained \\
\hline Moisture & 5.77 \\
Crude protein & 21.95 \\
Non-protein nitrogen & 1.62 \\
Protein nitrogen & 20.33 \\
Crude lipid & 1.21 \\
Fibre & 5.75 \\
Starch & 57.01 \\
Total sugars & 9.41 \\
Reducing sugars & 0.30 \\
Ash & 4.67 \\
Minerals (mg $\left.100 \mathrm{~g}^{-1}\right)$ & 9.93 \\
Iron & 19.39 \\
\hline Zinc
\end{tabular}

Adapted from Mune et al. [40] 


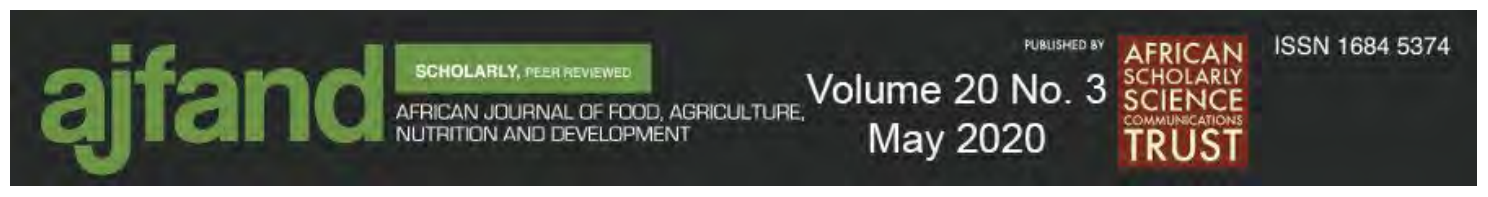

Table 2: Effect of Bradyrhizobium japonicum on Fe uptake in cowpea

\begin{tabular}{|l|l|l|l|l|}
\hline Treatments with & Root uptake & Shoot uptake & Pod uptake & Whole cowpea \\
of iron & of iron & of iron & uptake of iron \\
\hline$-\mathrm{R}\left(\mathrm{mg} \mathrm{plant}^{-1}\right)$ & $49.78 \mathrm{~b}$ & $63.84 \mathrm{~b}$ & $42.77 \mathrm{~b}$ & $156.39 \mathrm{~b}$ \\
\hline$+\mathrm{R}\left(\mathrm{mg} \mathrm{plant}^{-1}\right)$ & $65.81 \mathrm{a}$ & $93.62 \mathrm{a}$ & $76.03 \mathrm{a}$ & $235.46 \mathrm{a}$ \\
\hline
\end{tabular}

Note that different letters denote significantly different mean, adapted from Nyoki and Ndakidemi [31] 


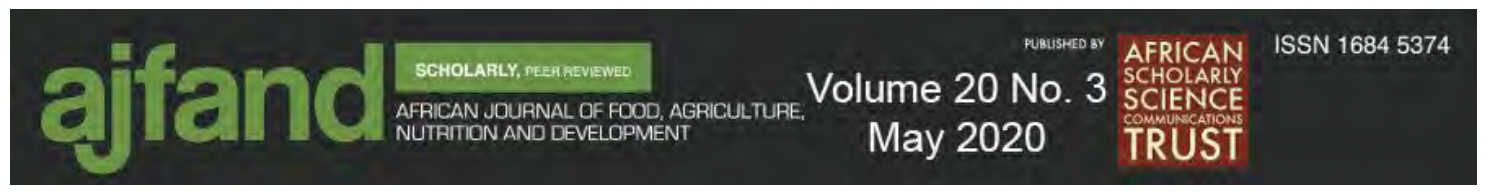

Table 3: Iron requirement of individuals by physiological maturity and/or sex

\begin{tabular}{ll}
\hline Age/sex & Quantity required $\left(\mathrm{Mg} \mathrm{day}^{-1}\right)$ \\
\hline $4-12$ months & 0.96 \\
$13-24$ months & 0.61 \\
2-5 years & 0.70 \\
6-11 years & 1.17 \\
12-16 years (girls) & 2.02 \\
12-16 years (boys) & 1.82 \\
Adult males & 1.14
\end{tabular}

Pregnant women

First trimester $\quad 0.8$

Second and third trimester $\quad 6.3$

Lactating women $\quad 1.31$

Menstruating women $\quad 2.38$

Postmenopausal women $\quad 0.96$

(Adapted from Abbaspour et al. [3] 


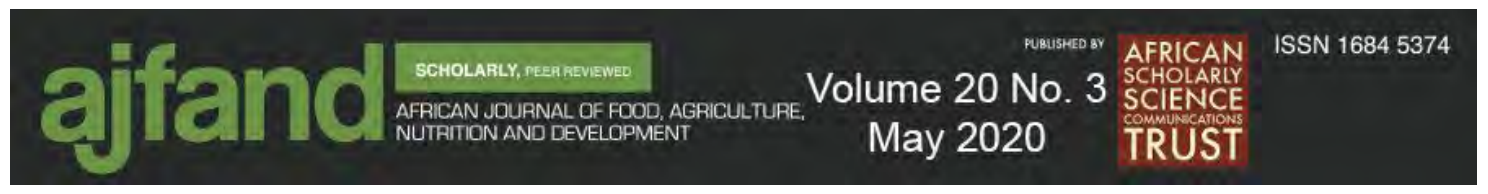

Table 4: Interventions for Fe supplementation and fortification

\begin{tabular}{|c|c|c|c|}
\hline Interventions & Description of the interventions & Pros & Cons \\
\hline Drug/Supplementation & $\begin{array}{l}\text { Ferrous salts are consumed } \\
\text { especially by pregnant women } \\
\text { and young people }\end{array}$ & $\begin{array}{l}\text { 1.Inaccessible } \\
\text { and/or } \\
\text { unaffordable } \\
\text { 2.Could induce } \\
\text { harmful side effect }\end{array}$ & $\begin{array}{l}\text { Contains } \\
\text { adequate iron } \\
\text { need of an } \\
\text { individual }\end{array}$ \\
\hline Food diversification & $\begin{array}{l}\text { Consumption of different food } \\
\text { sources rich in iron such as } \\
\text { meat, fruits and vegetables rich } \\
\text { in ascorbic acid to promote iron } \\
\text { absorption. Consumption of } \\
\text { fermented or germinated food } \\
\text { to enhance absorption and } \\
\text { reduction in consumption of tea } \\
\text { and coffee, which hinder non- } \\
\text { heme iron absorption }\end{array}$ & $\begin{array}{l}\text { Unaffordable by } \\
\text { rural poor }\end{array}$ & $\begin{array}{l}\text { Could satisfy iron } \\
\text { requirement of an } \\
\text { individual }\end{array}$ \\
\hline Food Fortification & $\begin{array}{l}\text { Addition of iron in food sources } \\
\text { during manufacturing; } \\
\text { fortification of wheat flour with } \\
\text { iron is the most common. }\end{array}$ & $\begin{array}{l}\text { Poor taste since } \\
\text { bioavailable forms } \\
\text { react with food } \\
\text { sources. These } \\
\text { fortified foods are } \\
\text { inaccessible by the } \\
\text { rural populace. It } \\
\text { delivers small } \\
\text { doses of the } \\
\text { nutrient }\end{array}$ & $\begin{array}{l}\text { Since food } \\
\text { sources are } \\
\text { fortified, it does } \\
\text { not cost extra to } \\
\text { purchase them }\end{array}$ \\
\hline
\end{tabular}




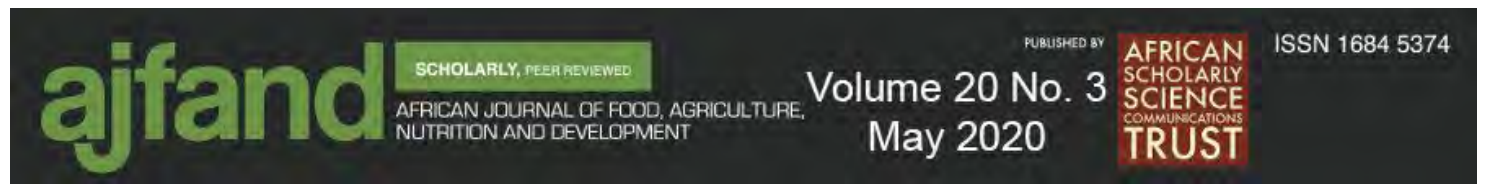

\section{REFERENCES}

1. Bhullar NK and W Gruissem Nutritional enhancement of rice for human health: the contribution of biotechnology. Biotechnol. Adv. 2013; 31 50-57.

2. AlChoubassi G, Aszyk J, Pisarek P, Bierla K, Ouerdane L, Szpunar J and R Lobinski Advances in mass spectrometry for iron speciation in plants. $\operatorname{Tr} A C$ Trends in Analytical Chemistry 2018; 104: 77-86, doi:https://doi.org/10.1016/j.trac.2017.11.006

3. Abbaspour N, Hurrell R and R Kelishadi Review on iron and its importance for human health. Journal of research in medical sciences: the official Journal of Isfahan University of Medical Sciences 2014; 19: 164.

4. Johnson DB, Kanao $\mathbf{T}$ and $\mathbf{S}$ Hedrich Redox transformations of iron at extremely low pH: fundamental and applied aspects. Frontiers in microbiology 2012; 3: 96.

5. Kobayashi T, Nozoye $\mathbf{T}$ and NK Nishizawa Iron transport and it is regulation in plants. Free Radical Biology and Medicine 2018; 10: 439

https://doi.org/10.1016/j.freeradbiomed.2018.10.439

6. Babalola OO and BR Glick The use of microbial inoculants in African agriculture: current practice and future prospects. Journal of Food, Agriculture and Environment (Finland) 2012; 10: 540-549.

7. Shenker $\mathbf{M}$ and $\mathbf{Y}$ Chen Increasing iron availability to crops: fertilizers, organofertilizers, and biological approaches. Soil Science \& Plant Nutrition 2005; 51: 117.

8. Kamara A, Omoigui L, Kamai $\mathbf{N}$, Ewansiha $\mathbf{S}$ and $\mathbf{H}$ Ajeigbe Improving cultivation of cowpea in West Africa. 2018.

9. Shetty A, Magadum S and K Managanvi Vegetables as sources of antioxidants. Journal of Food and Nutritional Disorders 2013; 2: 2.

10. Ayeni DF, Ikwebe $\mathbf{J}$ and FN Onyezili Iron and zinc levels in Vigna unguiculata (L.) Walp under varying phosphorus and fixed nitrogen treatment conditions. Food and Energy Security 2018; 7: e00141.

11. Babalola OO, Sanni AI, Odhiambo GD and B Torto Plant growth-promoting rhizobacteria do not pose any deleterious effect on cowpea and detectable amounts of ethylene are produced. World Journal of Microbiology and Biotechnology 2007; 23: $747-752$.

12. Zia-Ul-Haq M, Ahmad S, Amarowicz $\mathbf{R}$ and V De Feo Antioxidant activity of the extracts of some cowpea (Vigna unguiculata (L) Walp.) cultivars commonly consumed in Pakistan. Molecules 2013; 18: 2005-2017. 


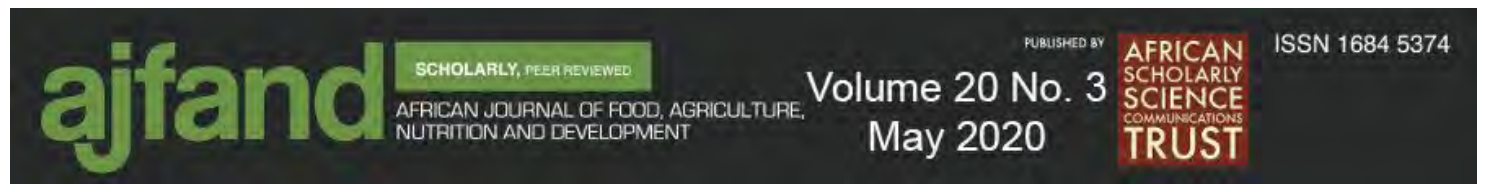

13. Mani M and B Vibha Effect of processing methods on phytic acid, total iron and iron bioavailability of cowpea. Asian Journal of Home Science 2013; 8: 51-54.

14. dos Reis Moreira-Araújo RS and AdCAS Brandão Foods Produced with Cowpea Flour as a Strategy to Control Iron Deficiency Anemia in Children. Current Topics in Anemia 2018; 257.

15. da Silva DOM and CAF Santos Adaptability and stability parameters of iron and zinc concentrations and grain yield in cowpea lines in the Brazilian semiarid region. Crop Science 2017; 57: 2922-2931.

16. Tak HI, Ahmad F and OO Babalola Advances in the application of plant growthpromoting rhizobacteria in phytoremediation of heavy metals. In Reviews of Environmental Contamination and Toxicology Volume 223, Springer: 2013; 3352.

17. Navarre DA, Shakya R and H Hellmann Vitamins, Phytonutrients, and Minerals in Potato. In Advances in Potato Chemistry and Technology (Second Edition), Elsevier: 2016; 117-166.

18. Osendarp $\mathbf{S}$ and $\mathbf{A}$ Eilander Iron deficiency and cognitive development. In Lifetime Nutritional Influences on Cognition, Behaviour and Psychiatric Illness, Elsevier: 2011; 94-108.

19. Sharma D, Jamra G, Singh UM, Sood S and A Kumar Calcium biofortification: three pronged molecular approaches for dissecting complex trait of calcium nutrition in finger millet (Eleusine coracana) for devising strategies of enrichment of food crops. Frontiers in plant science 2017; 7: 2028.

20. Colombo C, Palumbo G, He J-Z, Pinton $\mathbf{R}$ and $\mathbf{S}$ Cesco Review on iron availability in soil: interaction of Fe minerals, plants, and microbes. Journal of Soils and Sediments 2014; 14: 538-548.

21. Schmid NB, Giehl RF, Döll S, Mock H-P, Strehmel N, Scheel D, Kong X, Hider RC and $\mathbf{N}$ von Wirén Feruloyl-CoA 69-Hydroxylase1-Dependent Coumarins Mediate Iron Acquisition from Alkaline Substrates in Arabidopsis1 [C][W][OPEN]. 2014.

22. Morrissey $\mathbf{J}$ and ML Guerinot Iron uptake and transport in plants: the good, the bad, and the ionome. Chemical reviews 2009; 109: 4553-4567.

23. Jin CW, Li GX, Yu XH and SJ Zheng Plant Fe status affects the composition of siderophore-secreting microbes in the rhizosphere. Annals of botany 2010; 105: 835-841. 


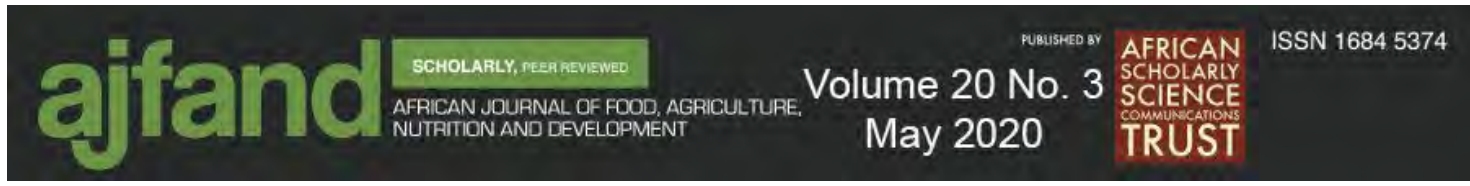

24. Uzoh IM and OO Babalola Rhizosphere biodiversity as a premise for application in bio-economy. Agriculture, ecosystems \& environment 2018; 265: 524-534.

25. Murgia I, Arosio P, Tarantino D and C Soave Biofortification for combating 'hidden hunger'for iron. Trends in plant science 2012; 17: 47-55.

26. Alori ET, Glick BR and OO Babalola Microbial phosphorus solubilization and its potential for use in sustainable agriculture. Frontiers in microbiology 2017; 8: 971.

27. Sonbarse PP, Sharma P and G Parvatam PGPR's mix treatment to Moringa improved plant growth and iron content in foliage as substantiated by biochemical and molecular methods. Journal of Plant Interactions 2017; 12: 526-532.

28. Verbon EH, Trapet PL and S Kruijs Temple-Boyer-Dury, C.; Rouwenhorst, T.G.; Pieterse, C.M. Rhizobacteria-mediated activation of the Fe deficiency response in Arabidopsis roots: impact on Fe status and signaling. Frontiers in plant science 2019; 10: 909.

29. Vacheron J, Desbrosses G, Bouffaud M-L, Touraine B, Moënne-Loccoz Y, Muller D, Legendre L, Wisniewski-Dyé $\mathbf{F}$ and $C$ Prigent-Combaret Plant growth-promoting rhizobacteria and root system functioning. Frontiers in plant science 2013; 4: 356.

30. Gadd GM Microbial influence on metal mobility and application for bioremediation. Geoderma 2004; 122: 109-119.

31. Nyoki D and PA Ndakidemi Influence of Bradyrhizobium japonicum and phosphorus on micronutrient uptake in cowpea. A case study of zinc $(\mathrm{Zn})$, iron (Fe), copper (Cu) and manganese (Mn). American Journal of Plant Sciences 2014; 5: 427.

32. Sessitsch A, Kuffner M, Kidd P, Vangronsveld J, Wenzel WW, Fallmann K and M Puschenreiter The role of plant-associated bacteria in the mobilization and phytoextraction of trace elements in contaminated soils. Soil Biology and Biochemistry 2013; 60: 182-194.

33. Rajkumar M, Ae N, Prasad MNV and H Freitas Potential of siderophoreproducing bacteria for improving heavy metal phytoextraction. Trends in biotechnology 2010; 28: 142-149.

34. Olanrewaju, OS, Glick BR and OO Babalola Mechanisms of action of plant growth-promoting rhizobacteria. World Journal of Microbiology and Biotechnology 2017; 33: 197.

35. Carson K, Holliday S, Glenn A and M Dilworth Siderophore and organic acid production in root nodule bacteria. Arch. Microbiol. 1992; 157: 264-271. 


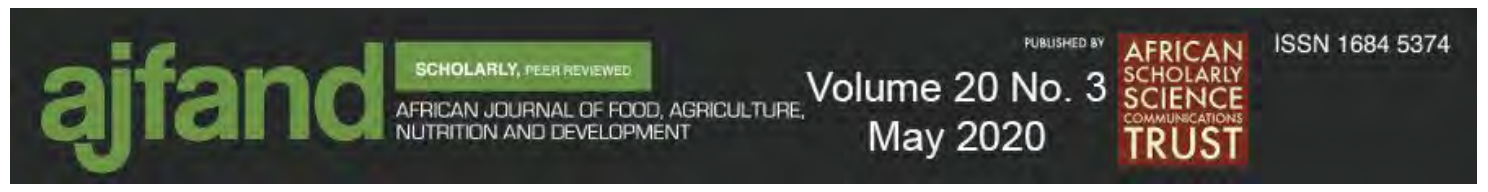

36. Schippers A Microorganisms involved in bioleaching and nucleic acid-based molecular methods for their identification and quantification. In Microbial processing of metal sulfides, Springer: 2007; 3-33.

37. Ayangbenro AS, Olanrewaju OS and OO Babalola Sulfate-reducing bacteria as an effective tool for sustainable acid mine bioremediation. Frontiers in Microbiology 2018; 9:1986. DOI: 10.3389/fmicb.2018.01986

38 Gadd GM Bioremedial potential of microbial mechanisms of metal mobilization and immobilization. Curr. Opin. Biotechnol. 2000; 11: 271-279.

39. Marschner H and V Römheld Strategies of plants for acquisition of iron. Plant Soil 1994; 165: 261-274.

40. Mune MM, Minka S and IL Mbome Chemical composition and nutritional evaluation of a cowpea protein concentrate. Global Advanced Research Journal of Food Science and Technology 2013; 2: 35-43.

41. Langyintuo A, Lowenberg-DeBoer J, Faye M, Lambert D, Ibro G, Moussa B, Kergna A, Kushwaha S, Musa S and G Ntoukam Cowpea supply and demand in West and Central Africa. Field crops research 2003; 82: 215-231. 